\title{
OPEN Transcriptomic analysis reveals new hippocampal gene networks induced by prolactin
}

Received: 3 January 2019

Accepted: 2 September 2019

Published online: 24 September 2019
Erika Alejandra Cabrera-Reyes ${ }^{1}$, América Vanoye-Carlo ${ }^{2}$, Mauricio Rodríguez-Dorantes ${ }^{3}$,

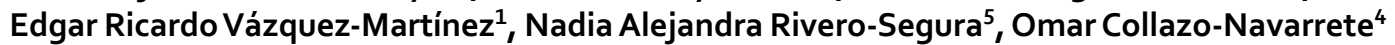
\& Marco Cerbón ${ }^{1}$

Prolactin (Prl) is a pleiotropic hormone with multiple functions in several tissues and organs, including the brain. In the hippocampus, Prl has been implicated in several functions, including neuroprotection against excitotoxicity in lactating rats and in Prl-treated ovariectomized animals. However, the molecular mechanisms involved in Prl actions in the hippocampus have not been completely elucidated. The aim of this study was to analyse the hippocampal transcriptome of female Prl-treated ovariectomized rats. Transcriptomic analysis by RNASeq revealed 162 differentially expressed genes throughout $24 \mathrm{~h}$ of Prl treatment. Gene Ontology analysis of those genes showed that 37.65\% were involved in brain processes that are regulated by the hippocampus, such as learning, memory and behaviour, as well as new processes that we did not foresee, such as glial differentiation, axogenesis, synaptic transmission, postsynaptic potential, and neuronal and glial migration. Immunodetection analysis demonstrated that Prl significantly modified microglial morphology, reduced the expression of $\mathrm{Cd} 11 \mathrm{~b} / \mathrm{c}$ protein, and altered the content and location of the neuronal proteins Tau, Map2 and Syp, which are involved in axogenic and synaptic functions. This novel delineation of Prl activity in the hippocampus highlights its importance as a neuroactive hormone, opens a new avenue for understanding its actions and supports its participation in neuronal plasticity of this brain area.

Prolactin is a pleiotropic hormone in vertebrates with more than 300 described functions that fall into five major categories: reproduction, brain processes and behaviour, growth and development, water and electrolyte balance, and immunomodulation ${ }^{1}$. The expression of $\mathrm{Prl}$ and its receptor have been detected at the transcriptional level in several brain areas, such as the olfactory bulb, corpus callosum, choroid plexus, amygdala, hypothalamus, thalamus, cerebral cortex and hippocampus ${ }^{2,3}$.

Physiological behaviours regulated by the hippocampus are complex and implicated in several brain processes, including storage and consolidation of spatial and declarative memory and acquisition and retrieval of information ${ }^{4}$. In this regard, Prl improves memory, cognition and learning ${ }^{5-8}$. In addition, Prl induces several processes, such as neurogenesis, neuronal proliferation and survival ${ }^{9-11}$, neuroplasticity and dendritic remodelling during pregnancy and in the postpartum period ${ }^{12,13}$, modulation of stress responses, calcium transport, and reduction of anxiety ${ }^{14-16}$. It has been found that Prl provides neuroprotection against excitotoxicity in the hippocampi of lactating rats ${ }^{17-21}$. Recently, it has been demonstrated that prolactin treatment induces changes in the expression of the prolactin receptor and reduces the excitotoxicity generated by glutamate in primary hippocampal neuronal cultures ${ }^{20}$. Additionally, in the same model, neuroprotection has been associated with a decrease in the $\mathrm{Ca}^{2+}$ overload observed during kainic acid-mediated excitotoxicity, therefore promoting survival of hippocampal neurons ${ }^{21}$.

Considering the pleiotropic functions of Prl, recent efforts have been dedicated to elucidating the mechanisms of action of this hormone in different body tissues, such as duodenal epithelial cells ${ }^{22}$, mammary epithelial cells ${ }^{23}$

${ }^{1}$ Unidad de Investigación en Reproducción Humana, Instituto Nacional de Perinatología-Facultad de Química, Universidad Nacional Autónoma de México. CDMX, México, 04510, Mexico. ${ }^{2}$ Laboratorio de Neurociencias, Instituto Nacional de Pediatría, SS. CDMX, México, 04530, Mexico. ${ }^{3}$ Instituto Nacional de Medicina Genómica, CDMX, México, 14610, Mexico. 'Laboratorio Nacional de Recursos Genómicos, Instituto de Investigaciones Biomédicas, Universidad Nacional Autónoma de México, CDMX, México, 04510, Mexico. ${ }^{5}$ División de Ciencias Básicas, Instituto Nacional de Geriatría, CDMX, México, 10200, Mexico. Correspondence and requests for materials should be addressed to M.C. (email: mcerbon85@yahoo.com) 
and pancreatic islets, by using transcriptomic approaches ${ }^{24}$. However, to the best of our knowledge, there is no information about Prl transcriptomic effects in the hippocampus.

Given that Prl regulates several brain processes, especially those that depend on the hippocampus, the present study aimed to elucidate the transcriptional effects of Prl in the hippocampus by means of transcriptomic analysis.

\section{Results}

Transcript abundance and differential regulation of gene expression induced by Prl treatment in the hippocampus. A total of $365,050,464$ reads, with a mean of 30.4 million reads $(2 \times 76$ bp paired-end reads), were obtained for total RNA from each hippocampus sample. Up to $93.5 \%$ of the reads were successfully mapped to transcripts contained in the NCBI Rnor 6.0 genome reference (Supplementary Table S1). Figure 1A shows the changes in gene expression at 3, 6 and $24 \mathrm{~h}$ post Prl treatment. In particular, Prl treatment modified the expression of 162 genes in the hippocampus of ovariectomized rats throughout the $24 \mathrm{~h}$ period, where 109 genes were upregulated and 53 were downregulated in Prl-treated rats compared to control rats (Supplementary Table S2). The differentially expressed genes after $3 \mathrm{~h}$ of Prl treatment included 53 upregulated genes and 23 downregulated genes (Fig. 1A).

Functional clusters of differentially expressed genes. During the time course of Prl treatment, persistent changes in gene expression were observed for five genes (Fig. 1B); three of the genes (Fmo2, Egr2 and Apol1) are involved in brain processes, and the other two were $S r p k 3$, a serine/threonine protein kinase, and $R h b d l 2$, a trans-membrane serine protease (Fig. 1B). The functional classification of each gene modified by Prl treatment was obtained from the Gene Ontology (GO) and Ensembl databases. The genes induced by Prl at 3, 6 and $24 \mathrm{~h}$ were mainly associated with cell cycle regulation $(28.0 \%, 36.1 \%$, and $27.0 \%$, respectively) and biological processes (23\%, $44 \%$ and $44 \%$, respectively); these genes represented more than $50 \%$ of the transcribed genes in each time period. Other biological processes were also represented, such as protein interactions, pathways and molecular functions (Fig. 1C and Supplementary Fig. S3A). In addition, few transcripts were related to disease processes, as shown in Supplementary Fig. S3A. In contrast, we detected several differentially expressed genes related to 32 brain processes (Fig. 1C), corresponding to $37.65 \%$ of all the differentially expressed genes. Interestingly, most of the genes differentially expressed after Prl treatment are involved in hippocampal functions such as learning, memory, microglial function, myelination, neurogenesis, neuroprotection, proliferation, remodelling, plasticity and hypoxia (Fig. 1C, purple bars, and Supplementary Fig. S3B). In particular, some of the induced genes (Ddr2, Adora2a, Egr2, Penk, Chat, and Sema3a) are involved in more than ten brain processes that are relevant to hippocampal functions (Fig. 1D).

Gene expression profiles related to brain processes changed throughout the time course of Prl treatment. Interestingly, the majority of genes were induced after $3 \mathrm{~h}$ of Prl treatment, which represents a primary response to Prl. In particular, 9 of 17 differentially expressed genes were involved in processes related to the extracellular matrix, differentiation, responses to oxidative stress, neurogenesis, proliferation, and brain and CNS development. However, after $6 \mathrm{~h}$ of treatment, we observed a reduction in the number of differentially expressed genes. The genes induced at this time point were related to brain and CNS development, axonal and synaptic transmission, learning and memory, and the extracellular matrix, and no more than four genes were involved in each process. Finally, after $24 \mathrm{~h}$ of $\mathrm{Prl}$ treatment, the most represented processes were learning and memory, homeostasis, brain and CNS development, and behaviour, and more than 8 genes were included for each process (Supplementary Table S4).

Since many differentially expressed genes were associated with several brain functions, the obtained results by RNASeq were validated for genes related to specific brain processes using RT-qPCR (Fig. 2 and Supplementary Tables S5, S6). The RT-qPCR analysis revealed the accuracy of the results obtained by RNASeq, and the expression results assessed by RT-qPCR are summarized in Fig. 2 and Supplementary Table S5.

Using GO data only for genes related to brain processes, we performed a correlation analysis between cell functions and gene expression (Fig. 3A), and a gene functional network was constructed (Fig. 3B). As observed in Fig. 3B, the most enriched network processes were those related to neurogenesis, differentiation, and CNS and brain development (blue lines); neurotrophic factors, the sleep-wake cycle, learning and memory, behaviour and microglia (cyan lines); facial nerve structural organization, axogenesis, and axonal and synaptic transmission (pink lines); and symmetric synapse, neuropeptide signalling and dendrite-related pathways (purple lines). Interestingly, this functional network in the hippocampus revealed that Prl induced genes related to sleep-wake cycle regulation, glial functions, myelination, and neuronal differentiation, which have previously been reported in other brain areas ${ }^{3}$. On the other hand, other processes, such as glial differentiation, axogenesis, synaptic transmission, postsynaptic potential, facial nerve structural organization, and neuronal and glial migration, amongst others, are new processes associated with Prl effects in the hippocampus.

A representative element network analysis that includes a summary of relations between genes and brain processes regulated by Prl is depicted in Supplementary Fig. S7. Importantly, as observed in this Figure, six genes (Drd2, Sema3a, Egr2, Chat, Penk and Adora2a) were involved in ten or more processes regulated by Prl. In this analysis, ten brain processes were highly regulated by Prl, represented by more than ten genes. These genes are related to behaviour, learning, memory and neurogenesis, which are classic hippocampal functions. However, other processes observed in this study, such as brain and CNS development, differentiation, remodelling and plasticity, have not been previously associated with $\mathrm{Prl}$ actions in the hippocampus.

Immunodetection analysis indicates that Prl modified the expression of microglia and neuronal proteins involved in hippocampal plasticity. To explore the effect of Prl treatment on hippocampal processes such as those related to microglia, axons and synaptic transmission that were observed in our GO and network analysis, we selected proteins related to these functions. First, to determine the effect of Prl treatment 
A)

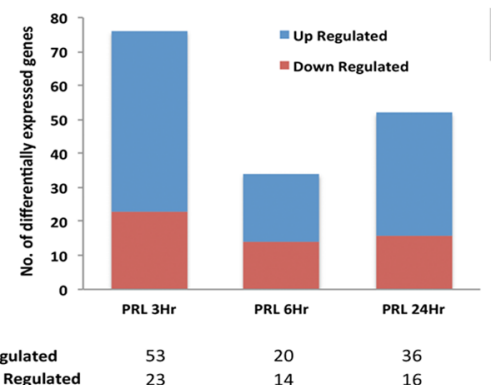

Up Regulated

C)

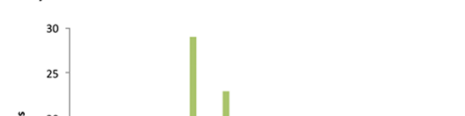

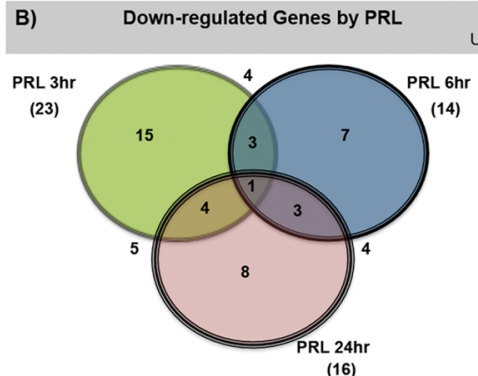

(16)

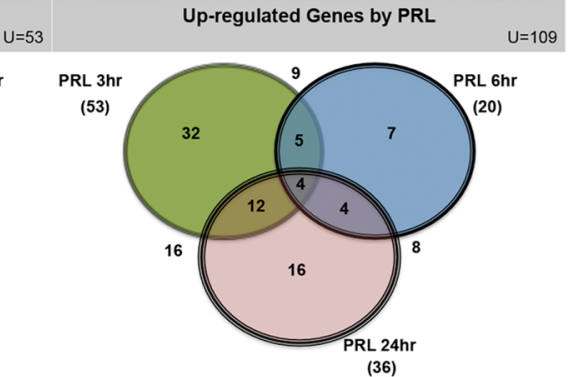

(36)

GO Functions
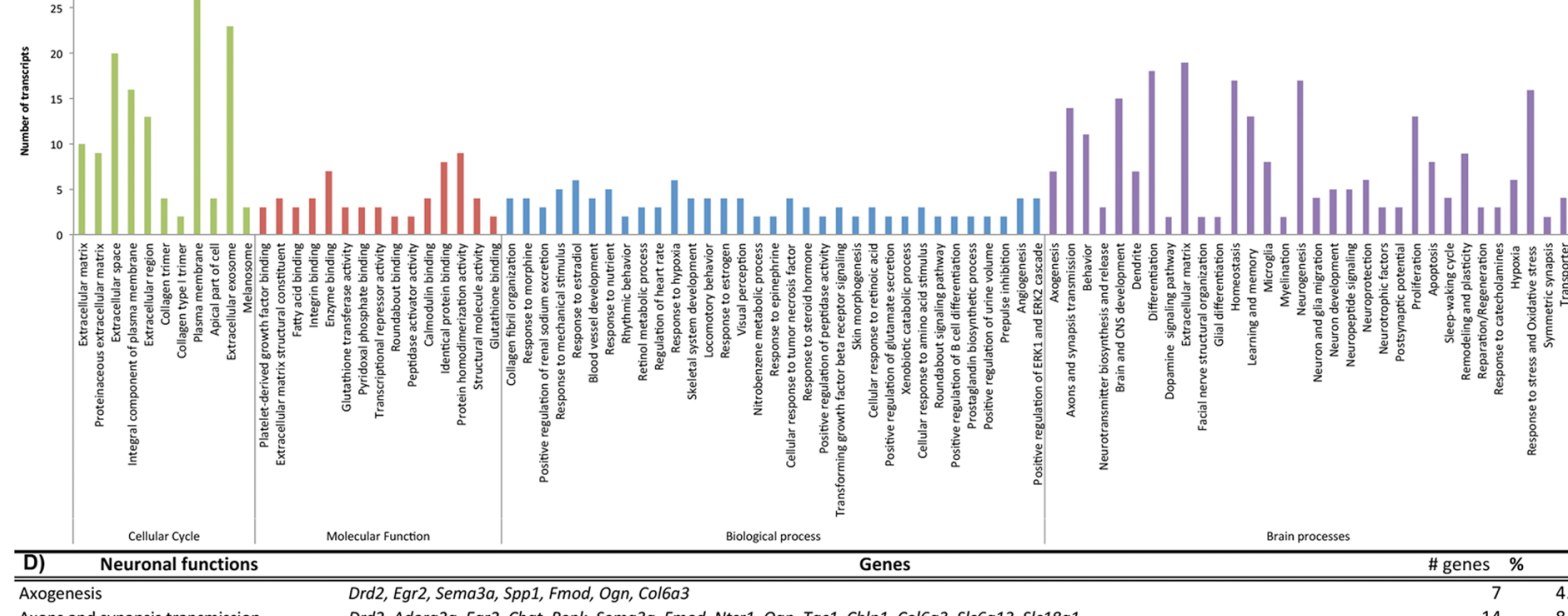

Axons and synapsis transmission

Behavior

Drd2, Egr2, Sema3a, Spp1, Fmod, Ogn, Col6a3

Genes

Drd2, Adora2a, Egr2, Chat, Penk, Sema3a, Fmod, Ntsr1, Ogn, Tac1, Cbln1, Col6a3, Slc6a13, Slc18a1

Drd2, Adora2a, Egr2, Chat, Penk, Ntsr1, Tac1, Alb, Ptgds, Gpr88, Prihr

Neurotransmitter biosynthesis and release Adora2a, Chat, Baiap3

Brain and CNS development Drd2, Adora2a, Egr2, Chat, Aldh1a2, Sema3a, Col3a1, Cbln1, Dct, Dll4, Ikzf1, Scn5a, Brca1, RGD1309108, Rgs9

Dendrite

Differentiation

Dopamine signaling pathway

Extracellular matrix

Facial nerve structural organization

Glial differentiation

Homeostasis

Learning and Memory

Microglia

Myelination

Neurogenesis

Neuron and glia migration

Neuron development

Neuropeptide signaling

Neuroprotection

Neurotrophic factors

Postsynaptic potential

Proliferation

Apoptosis

Sleep - waking cycle

Remodeling and plasticity

Reparation/Regeneration

Response to catecholamines

Hypoxia

Response to stress and Oxidative stress

Symmetric synapsis

Drd2, Adora2a, Penk, Sema3a, Ntsr1, Gnb3, Hdc

Drd2, Adora2a, Egr2, Aldh1a2, Mmp14, Sema3a, Spp1, Fmod, Ogn, Col3a1, Cbln1, Dct, Dll4, Ikzf1, Col1a1, Mfrp, Apold1, Ucma

$\operatorname{Drd} 2$, Rgs 9

Drd2, Penk, Mmp14, Sema3a, Spp1, Fmod, Ogn, Alb, Col1a2, Col3a1, Col1a1, Col6a3, Fap, Brca1, Coch, NEWGENE 621351, Aebp1, Gnb3, Pcolce

Egr2, Sema3a

Aldh1a2, Adora2a

Drd2, Adora2a, Spp1, Ntsr1, Tac1, Alb, lkzf1, Scn5a, Car3, Atp2c2, Gstm2, Gpr6, Malrd1, Mip, Mt1-ps1, Steap4, Acox2

Drd2, Adora2a, Egr2, Chat, Penk, Aldh1a2, Ntsr1, Tac1, Col1a2, Cblin1, Ttr, Gpr88, lp6k3

Drd2, Adora2a, Egr2, Chat, Tac1, Hif3a, Ttr, Car3

Alb, Egr2

Drd2, Adora2a, Egr2, Chat, Penk, Aldh1a2, Mmp14, Sema3a, Spp1, Fmod, Ogn, Col3a1, Cbln1, Dct, DIl4, Ikzf1, Mfrp

Drd2, Mmp14, Sema3a, Col3a1

Chat, Spp1, Fmod, Ogn, Mfrp

Penk, Ntsr1, Tac1, Ecel1, Prlhr

Chat, Aldh1a2, Mmp14, Spp1, Col1a2, Fmo2

Drd2, Dct, Ptgds

Adora2a, Ntsr1, Scn5a

Drd2, Egr2, Penk, Mmp14, Ogn, Tac1, Dct, Dll4, Scn5a, Fap, Fam83d, Igfbp2, Lmntd1

Adora2a, Aldh1a2, Sema3a, Ntsr1, Alb, Hif3a, Fap, Gfral

Drd2, Adora2a, Alb, Ptgds

Drd2, Adora2a, Egr2, Aldh1a2, Mmp14, Tac1, Col1a2, Ptgds, NEWGENE_621351

Aldh1a2, Ttr, Ecel1

Penk, Col1a2, Fcgr1a

Drd2, Chat, Penk, Mmp14, Hif3a, Apold1

Transporter

Penk, Ntsr1

Ptgds, Ttr, Atp2c2, Slc6a13

Figure 1. Prl induces changes in the expression of several genes involved in brain processes. (A) Summary of all the differentially expressed genes. (B) Venn diagram of the differentially expressed transcripts during time courses of Prl treatment. (C) Diverse categories of cell functions affected by Prl-regulated genes. All genes related to brain processes are shown in purple. (D) Numbers and percentages of Prl-regulated genes involved in brain processes.

on hippocampal microglia, we performed immunodetection of Cd11b/c, a b-integrin marker of microglial cells, in hippocampal tissue (the relations of this gene with other genes detected in our transcriptomic analysis are depicted in Supplementary Table S8). As shown in Fig. 4A, prolactin treatment had a notable effect on microglial cells of all hippocampal areas (CA1 and CA3). Cd11b/c expression was significantly decreased in the prolactin group compared to the control group, and the microglial projections were thinner (see inset in Fig. 4A). The analysis of cell immunolabelling density (area coverage, intensity of protein expression and number of particles 


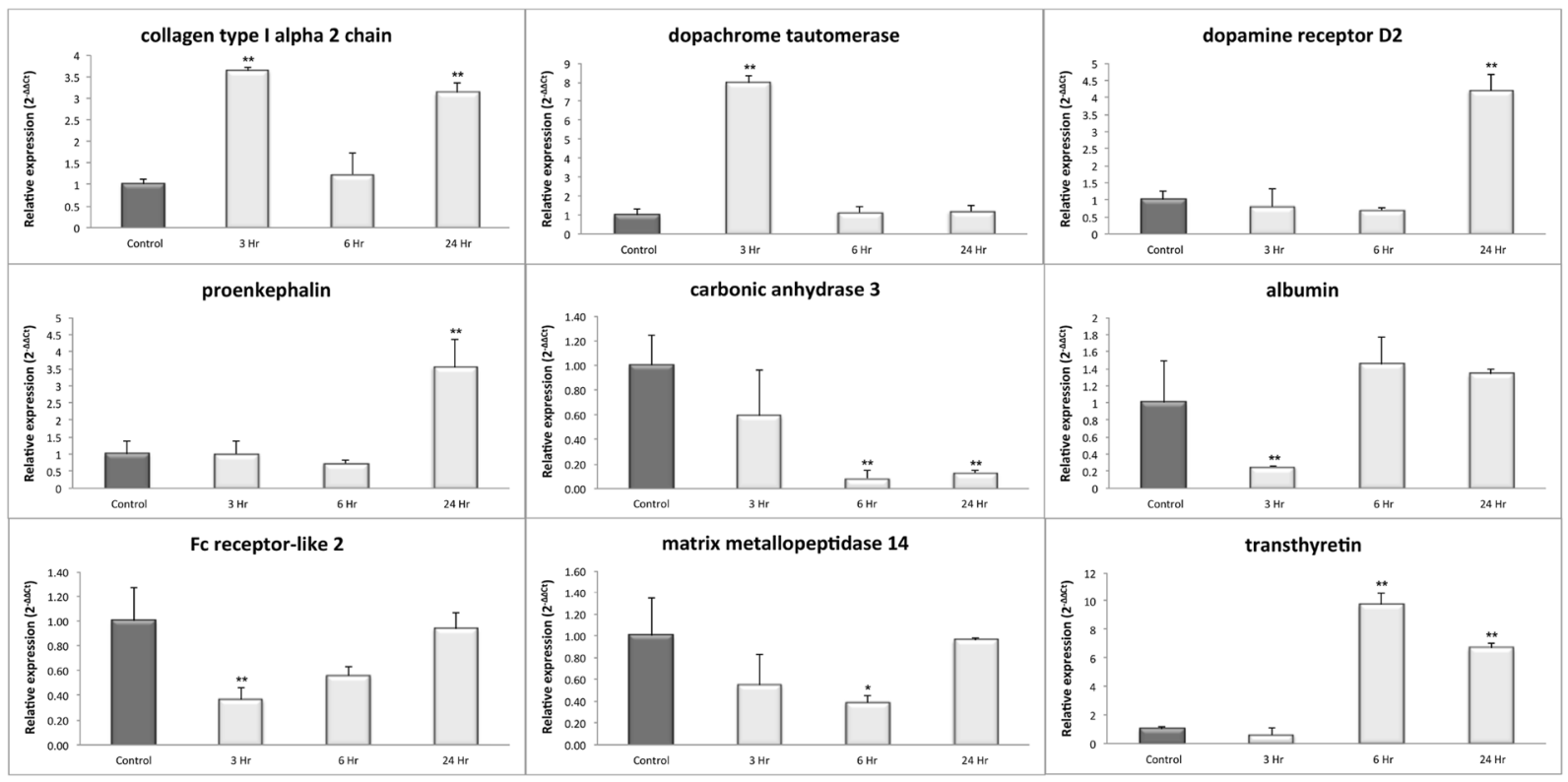

Figure 2. Validation of gene expression induced by Prl. RT-qPCR was used to validate nine genes with a Fc $>2$ by RNASeq analysis. Total RNA obtained from groups of animals treated with $\operatorname{Prl}(500 \mu \mathrm{g} / \mathrm{kg})$ in a time course experiment for 3,6 or $24 \mathrm{~h}$ or a control group $\left(\mathrm{NaCl}_{2}, 0.9 \%\right)$ was used for RT-qPCR. RNA of the internal control gene Hprt was used to calculate the relative expression of each gene according to the $2^{-\Delta \Delta \mathrm{Ct}}$ mathematic method. The light grey bars represent PRL treatment at 3,6 and $24 \mathrm{~h}$. The dark grey bars represent the expression control. The values are presented the mean $\pm S D, n=3$. $* p<0.05$ vs. control; $* * p<0.01$ vs. control (paired t-test).

expressing the protein) showed significant decreases in Prl-treated animals compared to control animals (Fig. 4BD, bar graphs).

Moreover, the expression of neuronal proteins, such as Tau, Map2 and Synaptophysin (Syp), was assessed (these proteins were also related to many genes induced in our transcriptomic analysis, as shown in Supplementary Table S8). Tau and Map2 are mainly involved in microtubule stability and cargo transport, while Syp is related to synaptic functions. Tau expression presented a significant increase in CA1 in neuronal somas, and its expression had greater intensity and area in neuronal projections of Prl-treated animals than in those of vehicle-treated animals (Fig. 5A,C,D). However, in CA3, this protein was localized in neuronal somas but was mainly localized in neuronal projections to the SR and was redistributed after PRL treatment, localizing with more intensity near the projections of neuronal somas (Fig. 5A). Interestingly, Map2 expression was localized in the projections of the stratum pyramidale, and no differences in intensity were detected between treatments; however, in CA1, the area covered was increased in the Prl group compared to the control group (Fig. 5B-D).

Figure 6A-C depicts Syp expression and quantitation. As observed, Syp expression in CA1 was almost absent in control animals, while Syp expression in the same region was slightly but not significantly increased in Prl-treated animals. In addition, in the CA3 region, a significant and marked increase in Syp expression was observed in PRL-treated animals compared with control animals that was localized in neuronal projections, mainly in the SR.

\section{Discussion}

The expression of the Prl gene and the Prl receptor (PrlR) have been described in different brain areas. Although PrlR protein has been found in the brain, the details of Prl protein expression are still controversial ${ }^{3}$. Furthermore, the effects of Prl on mental processes and behaviour in mammals, including humans, have been largely recognized. However, to the best of our knowledge, there is no information about Prl effects at the transcriptional level in the brain, particularly in the hippocampus.

The results of the current study indicate that Prl administration induces transcriptional activity in the hippocampi of OVX female rats. Prl effects at the transcriptional level were analysed in a time course experiment throughout $24 \mathrm{~h}$ after Prl administration. Among the time periods, the greatest number of differentially expressed genes was observed after $3 \mathrm{~h}$ of Prl treatment, and the differentially expressed genes were related to restructuring, remodelling, proliferation and neuronal development processes, indicating neuronal plasticity. Furthermore, after six hours of treatment, the processes in which Prl was involved were related to cognitive functions, synapses and neuronal development. In addition, $24 \mathrm{~h}$ after Prl administration, the activated processes were related mainly to mental functions such as learning, memory and behaviour, indicating a possible sequential role of Prl regulation in hippocampal processes and functions; furthermore, it is notable that PRL principally exerted a primary transcriptional effect followed by a secondary transcriptional response. Indeed, of all the genes that were differentially expressed throughout the $24 \mathrm{~h}$ period after Prl treatment, $37.65 \%$ were related to brain processes (Fig. 1 and Supplementary Fig. S3). Importantly, to explore the brain processes activated by Prl, we studied the expression of 


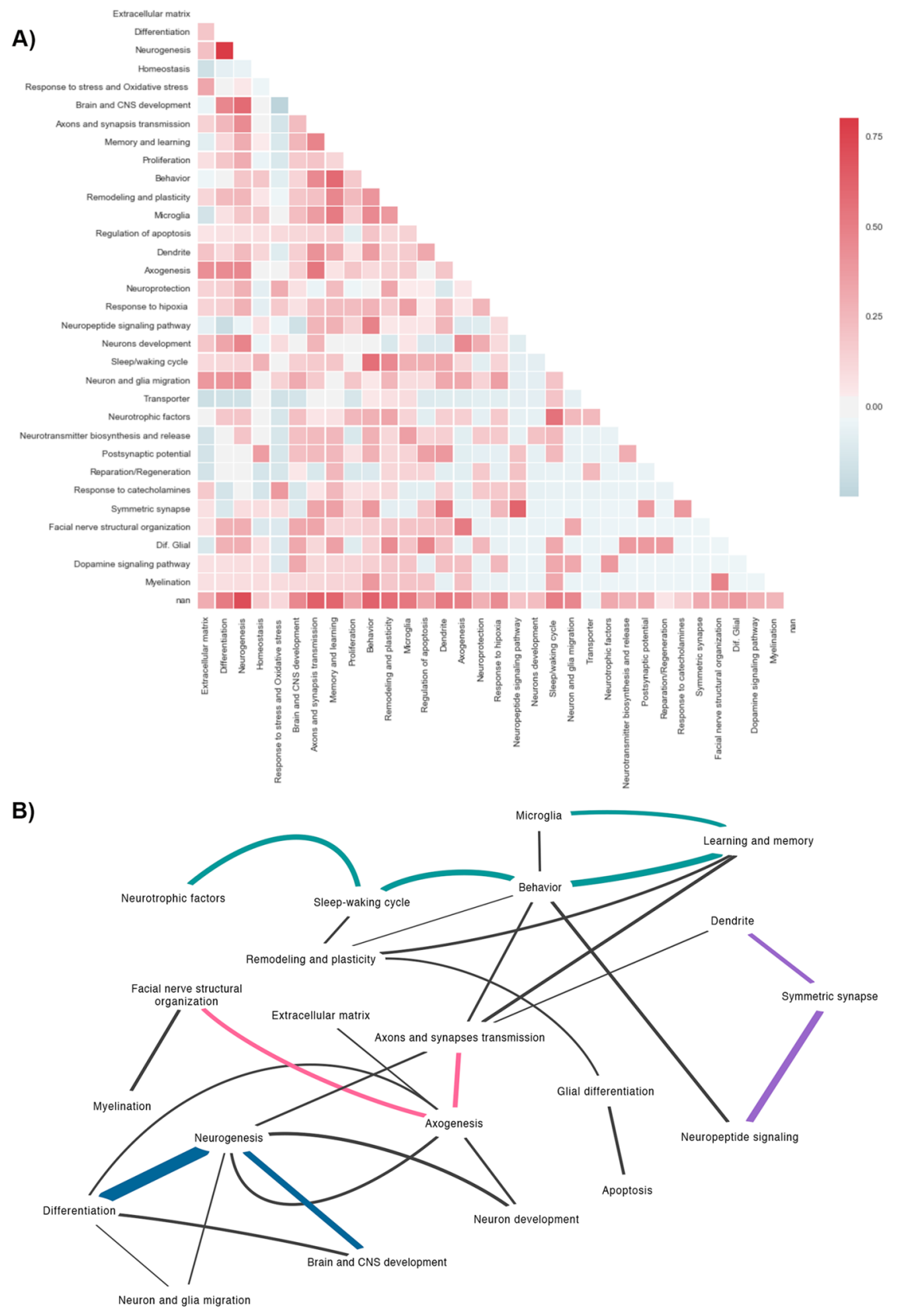

Figure 3. Correlation of Prl-induced gene expression associated with brain processes. Pearson correlation analysis between Prl-induced gene expression and induced functions was performed using Python 3.5 packages (matplotlib, numpy, matplotlib.pyplot, pandas networkx, and seaborn) and Cytoscape 3.6.1. (A) Heatmap of correlated functions. The strongest positive correlations and the strongest negative correlations between gene expression and brain processes are shown in red and blue, respectively. (B) A correlation network of main brain processes and genes is depicted. Main brain processes related to clusters of genes are shown in pink, cyan, blue and purple; the line thickness is proportional to the number of genes that are interacting.

proteins related to microglia and neuronal plasticity. Interestingly, treatment with Prl modified the expression and location of the microglial activation protein $\mathrm{Cd} 11 \mathrm{~b} / \mathrm{c}$ as well as neuronal proteins such as Tau, Map2 and Syp, all of which are involved in neuronal plasticity.

Although Prl was discovered at the beginning of the last century, there is little information on the molecular mechanisms through which Prl regulates neuronal functions. It is known that Prl regulates specific neuronal circuits and participates in many brain functions, including maternal behaviour, energy balance and food intake, sleep, anxiety, neurogenesis, and migraine and pain, among others ${ }^{11,14,25-30}$. A recent review by Patil and coworkers ${ }^{16}$ highlighted the effects of Prl in neuron excitability, describing the critical effects of this hormone on membrane receptor potential thresholds and/or neurotransmission efficiency. The authors concluded that the action of Prl in neurons is mainly exerted through regulation of neuronal excitability and channels, such as TRPV1, 
A)

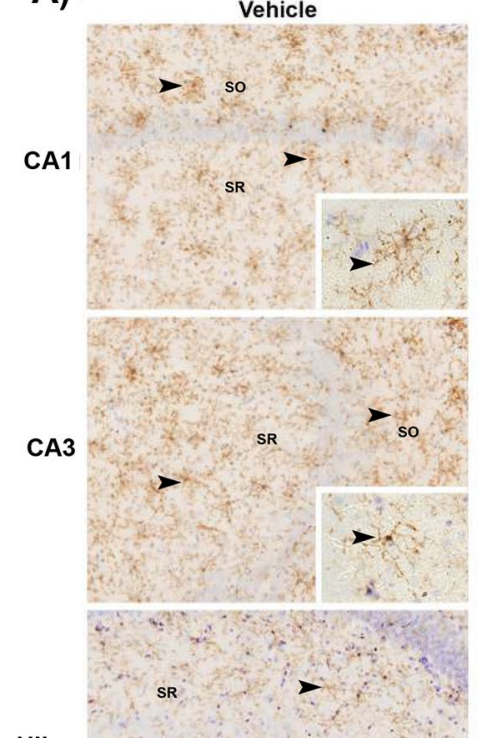

Hilus

DG

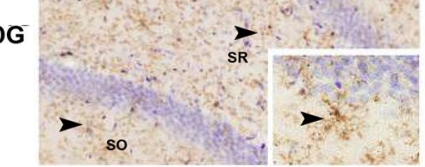

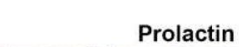

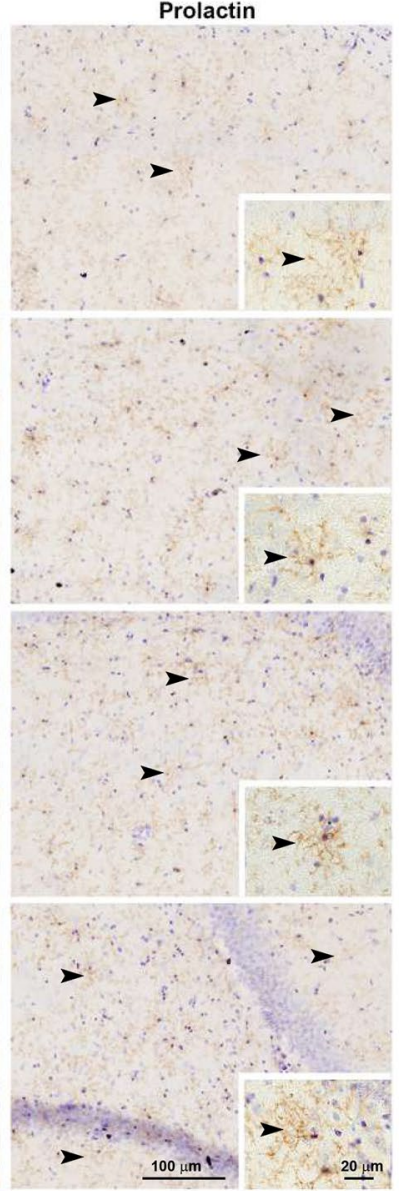

B)

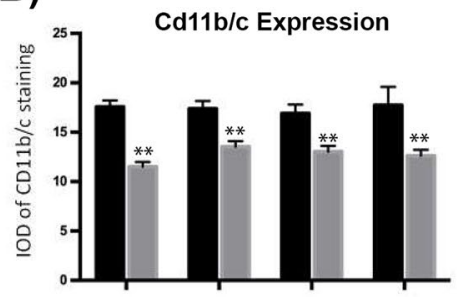

c)

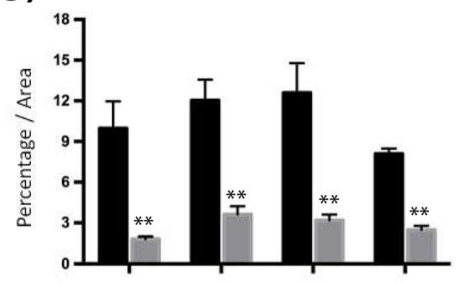

D)

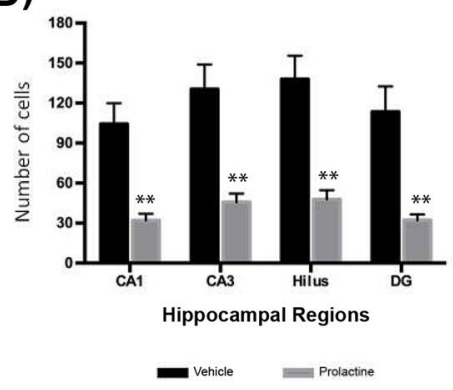

Figure 4. Prolactin induces attenuation of microglial activation in the hippocampus. Immunohistochemistry for $\mathrm{Cd} 11 \mathrm{~b} / \mathrm{c}$ was performed in the hippocampus. (A) Immunostaining of $\mathrm{Cd} 11 \mathrm{~b} / \mathrm{c}$ in hippocampal subfields (CA1, CA3, hilus and DG) from animals treated with vehicle and Prl is shown with details of microglial morphology (inset). Quantitative analyses of (B) Cd11b/c expression, (C) the areas covered by microglia, and (D) the numbers of particles expressing $\mathrm{Cd} 11 \mathrm{~b} / \mathrm{c}$ in each hippocampal region are also shown. Significant differences were lower than $\mathrm{p} \leq 0.001$ by t-test $(* *)$. Scale bars $=100 \mu \mathrm{M}$ and $20 \mu \mathrm{M}$.

TRPA1, and TRPM8 ${ }^{16}$. However, the precise gene expression changes associated with these important functions have not been explored. Our results provide the molecular basis for defining the functional impact of Prl in the hippocampus.

In this study, transcriptomic analyses indicated that Prl induces the expression of different sets of genes involved in brain processes related to learning, behaviour, memory, neuroprotection, neurodevelopment, neurogenesis, remodelling, plasticity, and sleep/waking regulation, among others (Figs 1,3). These processes have been previously found to be related to Prl functions in this brain area ${ }^{3}$. Furthermore, the data analyses indicated that other important processes, such as glial differentiation, axogenesis, synaptic transmission, postsynaptic potential, facial nerve structural organization, and neuronal and glial migration, might also be regulated by Prl in the hippocampus (Fig. 3, Supplementary Fig. S7).

We were able to detect six genes induced by $\operatorname{Prl}(\operatorname{Drd} 2$, Sema3A, Egr2, Chat, Penk and Adora2a), and importantly, each of these genes was associated with the regulation of more than ten brain functions and processes (Fig. 3, Supplementary Fig. S7) related to axons as well as synaptic transmission and microglial regulation. Considering the characteristics of these genes, we think that these genes may play major roles in hippocampal functions and that they deserve to be further studied.

Other genes, such Ador2a, Car3, Chat, Drd2, Egr2, Hif3a, Notch, Penk, Tac1 and Ttr, which were also differentially expressed after Prl treatment, are involved in maintaining microglial functions. Interestingly, these genes have been reported to be altered in neuroinflammation, neurodegenerative diseases, and psychiatric disorders ${ }^{31-39}$. It is possible that genes related to microglial functions induced by Prl might play roles in neuro-immunomodulation in the hippocampus or in preventing neuronal cell damage. This idea is consistent with previous reports that Prl confers neuroprotection in excitotoxicity models ${ }^{3,17,18,40}$. It is important to note that microglia have been related to either neurodegenerative or neuroprotective processes depending on their 
A)
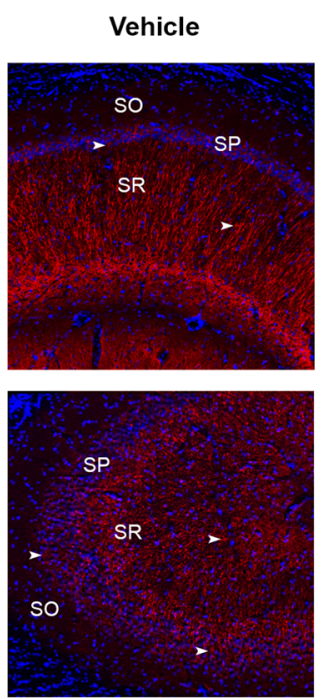

C)

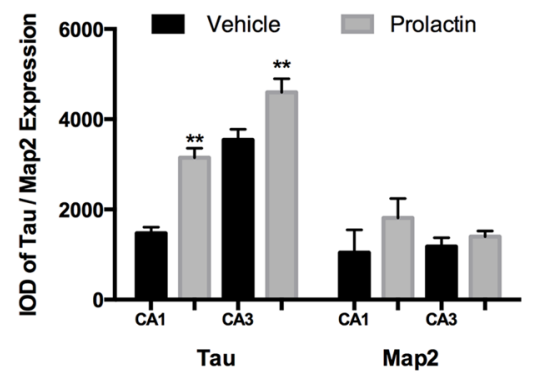

B)
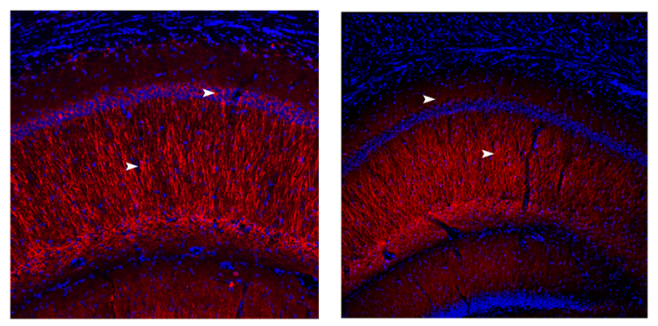

Vehicle
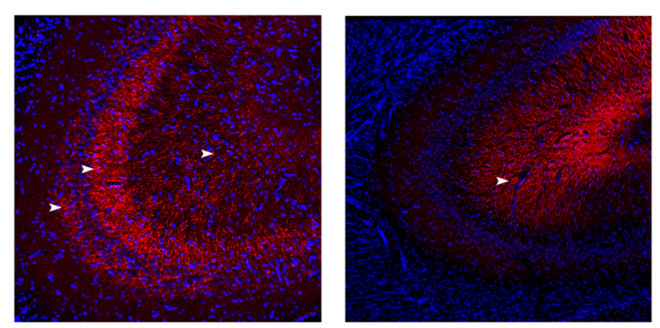

D)

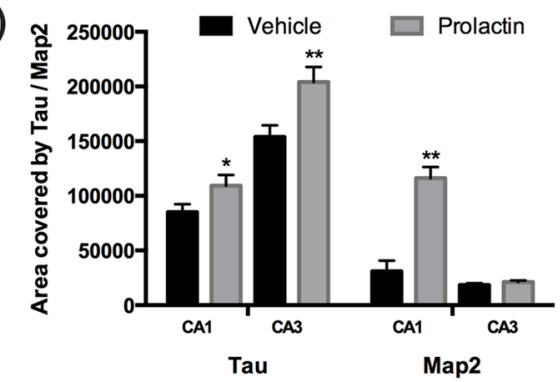

Prolactin
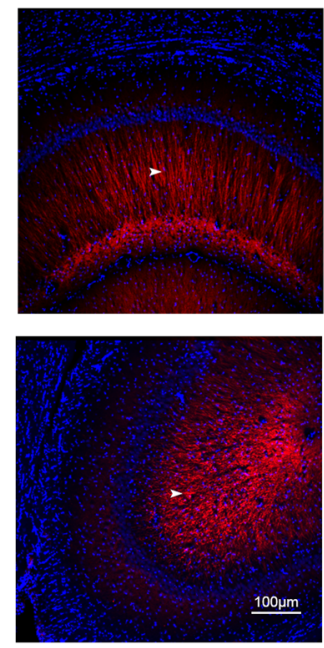

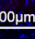

Figure 5. Prolactin treatment modifies the cellular location and content of Tau and Map2 proteins in the hippocampus. Immunohistochemistry against total Tau and Map2 proteins in hippocampal tissues was performed. (A) Tau protein detection in hippocampal subfields (CA1 and CA3) in animals treated with vehicle compared with those treated with Prl. Changes in SO and SR were detected. (B) Map2 protein detection in the hippocampus. Major changes were detected in the somas of pyramidal cells (stratum oriens: SO, stratum pyramidale: SP, and stratum radiatum: SR). Nuclei were counterstained with DAPI (blue). Scale bar $=100 \mu \mathrm{M}$.

activation state. Whether prolactin neuroprotection is a consequence of direct effects of Prl on microglial cells or to Prl-mediated inhibition of a non-classic excitotoxicity pathway has yet to be elucidated.

In this regard, our results demonstrated that Prl modified microglial activation after $24 \mathrm{~h}$ of Prl treatment, which was shown by a significant decrease in the expression of the Cd11b/c marker (Fig. 4). This observation supports and extends the idea that Prl may modulate microglial functions, which was previously reported by Möderscheim et al. in a study indicating that Prl is primarily involved in a gliogenic response during recovery from cerebral injury ${ }^{41}$. Many other functions of glial cells have been reported; for example, microglia engulf and remodel developing and mature synapses ${ }^{32}$. Moreover, microglia contribute to good connectivity during normal assembly of brain circuits ${ }^{34}$. Considering that the Prl receptor is present in primary cell cultures of hippocampal neurons ${ }^{20}$, it is important to determine whether Prl may participate in these processes during hippocampal development and in the adult brain.

Furthermore, it has been widely reported that microglia play important roles in several physiological processes not related to pathological conditions, such as axogenesis, neurogenesis and synaptogenesis; these processes are also affected by $\mathrm{Prl}^{42}$. Further studies are required to establish whether microglial activation, as well as morphological changes in microglia, are related to the neuroprotective effect induced by prolactin. In another study, long after rats were ovariectomized, Prl binding sites and serum prolactin levels were found to be reduced in many brain areas ${ }^{43}$; in addition, long-term ovariectomy causes cognitive dysfunction associated with neurogenesis, synaptic plasticity and immune modulation and also induces changes in the hippocampal transcriptome ${ }^{44}$. In our study, we showed that prolactin treatment in short-term ovariectomized rats reduced microglial activation and caused morphological changes in microglial cells (Fig. 4), which may be related to microglial functional recovery. However, more investigation will be required to explore this effect.

On the other hand, it has been reported that upregulation of the adenosine A2A receptor protein (Adora2a) in neurons is associated with synaptic impairment ${ }^{45}$. Interestingly, increased Adora2a gene expression has been associated with neurogenesis and hippocampal volume in Alzheimer patients ${ }^{46}$, which is a very interesting finding that should be further explored.

The remarkable modification of gene expression induced by Prl related to hippocampal processes led us to evaluate proteins involved in some of these brain processes. We performed a series of experiments to detect 
A)
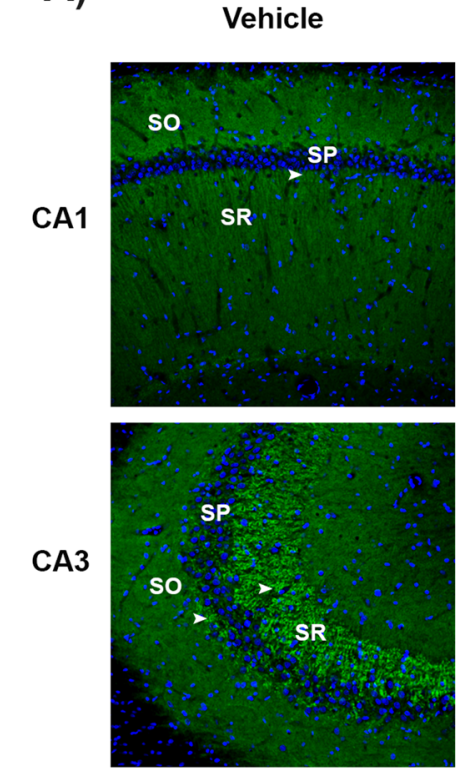

Prolactin
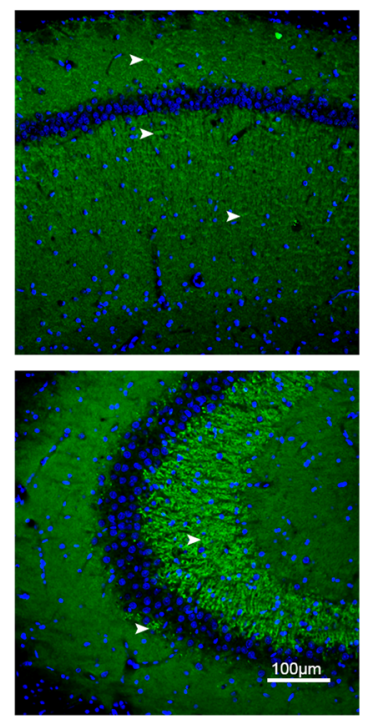

B)

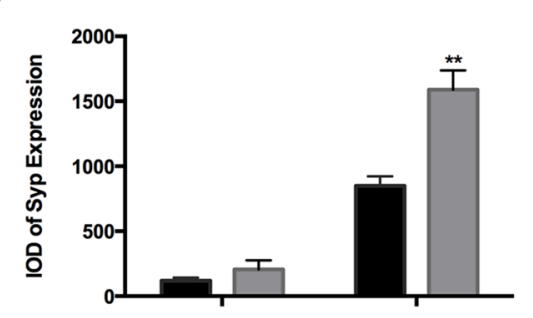

C)

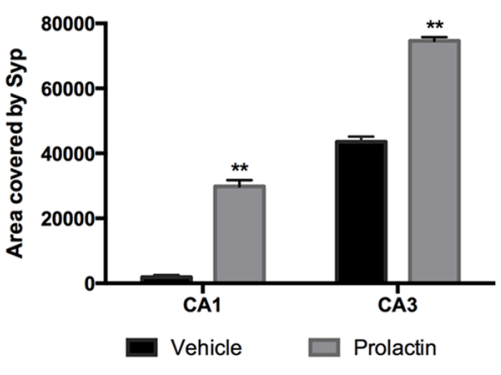

Figure 6. Prolactin treatment modifies the cellular location and expression of Syp protein in the hippocampus. Immunohistochemistry against total Syp protein in hippocampal tissues was performed. (A) Syp protein detection in hippocampus subfields (CA1 and CA3) in animals treated with vehicle compared with those treated with Prl (stratum oriens: SO, stratum pyramidale: SP, and stratum radiatum: SR). Nuclei were counterstained with DAPI (blue). Scale bar $=100 \mu \mathrm{M}$.

changes in neuronal proteins, such as Tau and Map2, that are involved in axonal transport and synaptic plasticity. After Prl treatment, these proteins showed marked changes in their expression and localization (Fig. 5). These neuronal proteins have been largely recognized as modulators of neuronal plasticity, thus suggesting that Prl has an effect in neuronal plasticity. We also evaluated a neuronal protein involved in synaptic transmission, Syp. Indeed, Prl treatment also markedly modified the expression and neuronal localization of this protein, as shown in Fig. 6. Thus, the changes observed in this protein, namely, increased expression and changes in cellular localization after Prl treatment, suggest that this protein plays a role in the modulation of synaptic function and reinforces the idea that this may be a Prl function in the hippocampus. This proposal is consistent with our recent report, which revealed that Prl induced an increase in the expression of vesicular glutamate transporter 1 in the hippocampus concomitantly with an increase in the expression of PrlR ${ }^{47}$. However, the possible effects of Prl on excitatory and inhibitory synaptic transmission require further investigation.

On the other hand, hippocampus-dependent plasticity has been shown to be related to genes such as $\operatorname{Prd} 2$, which plays a major role in the regulation of hippocampal learning and memory ${ }^{48}$ as a modulator of microglial function during neuroinflammation ${ }^{49}$ and in preventing damage by reducing inflammation ${ }^{50}$. Interestingly, Drd 2 gene expression was highly regulated by Prl in this study. Furthermore, other differentially expressed genes regulated by Prl, such as Ntsr1, have been shown to contribute to different neuronal functions. Ntsrl plays a role in the induction of long-term potentiation at granular cell synapses ${ }^{51}$. Interestingly, Cbln1 can induce changes in dynamic axonal structure during cerebellar synapse formation ${ }^{52}$. Furthermore, Sema3a regulates neuronal morphogenesis through polarization of dendrite/axon formation in hippocampal neurons in primary cell cultures ${ }^{53}$. Whether these genes induced by $\mathrm{Prl}$ in the hippocampus play similar roles in other brain areas is a question that needs to be further explored.

Surprisingly, we found that Prl modulates many genes of the extracellular matrix, which have been reported to prevent ageing ${ }^{54}$. In particular, genes such as Colla1 Colla2, Fmod, Ptgds, and Aldh1a2 are induced by exercise training and have been found to prevent hippocampal ageing in an Alzheimer's disease model of animals with premature ageing. Remarkably, we found that all of the above genes were induced in the hippocampus by Prl (Fig. 1D and Supplementary Table S2), suggesting a possible important role for Prl in preventing ageing in the hippocampus. However, further studies are required to assess this possibility.

In addition, some genes found in the current study display many brain functions, such as the Penk gene, which is induced during neuronal excitation in the hippocampus and is involved in neuroprotection against kainic acid in a ketogenic protective diet ${ }^{55}$. This gene is also overexpressed in dopaminergic tuberoinfundibular neurons of pregnant, pseudopregnant, lactating and aged rats, suggesting that this gene is regulated by Prl, as confirmed by the present study ${ }^{56}$. Furthermore, stress increases Prl synthesis, which subsequently induces Penk expression in the parvocellular subset of the paraventricular nucleus, suggesting that Prl regulation of Penk expression participates in reducing damage induced by stress ${ }^{57}$. However, the complete function of this gene in the hippocampus requires further elucidation.

In the field of psychiatry, the adverse effects of Prl remain under debate. Treatment with psychiatric drugs to manage schizophrenia and depression is frequently associated with hyperprolactinemia (HPL), suggesting the 
negative effects of Prl in these patients ${ }^{58,59}$. In contrast, in a recent study, it was shown that many patients with a first episode of psychosis presented HPL before treatment and presented elevated rates of HPL over the course of the illness ${ }^{60}$. Further studies are required to determine whether HPL alters brain processes during the course of disease and treatment or whether HPL may be involved in a compensatory mechanism to maintain brain tissue homeostasis in these patients. The finding of this study that Prl seems to fine-tune gene expression regulation in the hippocampus opens up a novel field of research on psychiatric diseases.

In conclusion, the overall results of this study support and extend the idea that Prl is a neuroactive hormone that induces transcriptional effects in several sets of genes that may be involved in several hippocampal functions, including neuronal plasticity.

\section{Materials and Methods}

Animals. Adult virgin female Wistar rats (250-300 g) were individually housed under a controlled temperature and photoperiod (12:12 h light:dark cycle, lights on at 06:00), with food and water available ad libitum. To produce ovariectomized (OVX) rats, the ovaries were surgically removed under anaesthesia $(0.2 \mathrm{ml} / 100 \mathrm{~g}$ of body weight, intraperitoneal administration of a cocktail of $87.5 \mathrm{mg} / \mathrm{kg}$ ketamine and $12.5 \mathrm{mg} / \mathrm{kg}$ xylazine, Cheminova de México, México), and Prl treatment was started 2 weeks after surgery. Three rats from each group were randomly assigned to each of four groups: the vehicle group, the Prl 3 group, the Prl 6 group, and the Prl $24 \mathrm{~h}$ group. The Institutional Animal Care and Use Committees of the School of Chemistry at the National Autonomous University of Mexico approved all experimental protocols. The animals were handled in accordance with the National Institutes of Health Guide for the Care and Use of Laboratory Animals and the Official Mexican Guide of the Ministry of Agriculture (SAGARPA NOM-062-Z00-1999) published in 2001. All efforts were made to minimize suffering and the number of animals used.

Treatments. OVX rats were treated once, intraperitoneally, with a single dose of Prl from the sheep pituitary (Sigma-Aldrich, L6520) $(500 \mu \mathrm{g} / \mathrm{kg}$ in $100 \mu \mathrm{l}$ of $0.9 \%$ sterile saline solution) or with a control solution $(100 \mu \mathrm{l}$ of $0.9 \%$ sterile saline solution). The groups were as follows: one control group treated with vehicle and three Prl groups treated for 3,6 and $24 \mathrm{~h}$.

RNA extraction. For RNA extraction, the hippocampi were dissected from the animals. Total RNA was extracted with an RNeasy Plus Mini Kit Qiagen (Qiagen, 74004) following the manufacturer's instructions. The RNA was quantified, and the integrity was assessed with both a NanoDrop (model ND-1000) and an Agilent 2100 Bioanalyzer prior to library preparation.

RNASeq. Total RNA ( $2 \mu \mathrm{g})$ was used for library preparation, according to the manual of the TruSeq Stranded mRNA Library Prep Kit (Illumina, 20020595). Libraries with fragments of 250-450 bp were sequenced as 76 base pair paired-end reads by the Unidad Universitaria de Secuenciación Masiva y Bioinformática (UNAM) using a NextSeq. 500 platform (Illumina). A total of 365,050,464 reads and a mean of 30.4 million reads $(2 \times 76 \mathrm{bp}$ paired-end reads) were obtained for the total RNA from each hippocampus sample.

Data analysis. The sequence output in FastQ format was screened for quality using FastQC software provided by Babraham Bioinformatics (http://www.bioinformatics.babraham.ac.uk/projects/fastqc/), and alignment was carried out with the rat genome downloaded from NCBI (GCF_000001895.5_Rnor_6.0_genomic.fna.gz) using the Smalt program with its default values. For all the samples, coverage calculation by gene was carried out with the BamTools BED coverage tool using the NCBI GFF file GCF_000001895.5_Rnor_6.0_genomic.gff.gz, and an alignment exceeding $93 \%$ was obtained after filtering for only genes. The matrix result was introduced into IDEAmex (http://zazil.ibt.unam.mx/ideamex), and NOISeq, DESeq, EdgeR and DESeq. 2 were for differential expression analysis using an FDR (false discovery rate) of 0.05 and a $\log 2$ (fold change) of 1 . Genes with differential expression $\geq 2$-fold or $\leq 2$-fold were included in the analysis.

Correlations and networks were analysed with Pearson correlation analysis between Prl-induced gene expression and gene functions using Python 3.5 packages (matplotlib, numpy, matplotlib.pyplot, pandas networkx, and seaborn) and Cytoscape 3.6.1.

Functional clustering. To perform functional annotation clustering, the gene IDs for the differentially expressed genes (both upregulated and downregulated) were uploaded into the DAVID v6.7 ${ }^{61}$; the gene IDs used were the official names converted to symbols, which are compatible with the DAVID.

RT-qPCR. Validation was performed to verify the expression of selected genes, the RNA used for RNASeq. The genes subjected to validation were Ttr, Drd2, Car3, Gfral, Col1a2, Dct, Mmp14, Egr2 and Fcrl2. The RNA was quantified on a NanoDrop ND-1000 (Thermo Scientific, USA), and cDNA was reverse-transcribed using a Reverse Aid First Strand cDNA Synthesis Kit (Thermo Scientific, USA) according to the manufacturer's instructions with polyT primers. RT-qPCR was performed using TaqMan ${ }^{\circledR}$ Fast Universal PCR Master Mix (Applied Biosystems) under the following conditions: $95^{\circ} \mathrm{C}$ for $20 \mathrm{~s}$ followed by 40 cycles of $95^{\circ} \mathrm{C}$ for $1 \mathrm{~s}$ and $60^{\circ} \mathrm{C}$ for $20 \mathrm{~s}$. RT-qPCR was performed using a StepOne Plus Real Time PCR system (Applied Biosystems, USA). All run results were normalized to the Hprt control for analysis. Sequence Detection Software 1.3 (Applied Biosystems) was used for data analysis. The comparative CT method $\left(2^{-\Delta \Delta \mathrm{CT}}\right)$ was used to calculate the relative changes in target gene expression. The average and standard deviation of $2^{-\Delta \Delta C T}$ were calculated for the three independent experiments. Applied Biosystems supplied the probes for all genes. All assays were purchased from Applied Biosystems (see additional file Supplementary Table S6 for the primer sequences and amplicon lengths). 
Transcardial perfusion fixation of the CNS. For tissue extraction, rats were anaesthetized with pentobarbital (Sigma-Aldrich, St. Louis, MO) and perfused transcardially with $250 \mathrm{ml}$ of PBS (0.1 M; pH 7.4) followed by $250 \mathrm{ml}$ of $4 \%$ paraformaldehyde in $\mathrm{PBS}\left(\mathrm{pH} 9.5,10^{\circ} \mathrm{C}\right)$. The brains were removed, post-fixed in the same fixative overnight and cryoprotected with $20 \%$ sucrose for $2-3$ days at $4{ }^{\circ} \mathrm{C}$. Coronal sections $(30 \mu \mathrm{M})$ were cut through the dorsal hippocampus on a freezing microtome, and the serial cuts were collected and stored in cryoprotectant solution ( $30 \%$ ethylene glycol and $30 \%$ glycerol in PBS) at $-20^{\circ} \mathrm{C}$. Three tissue sections were employed for each round of staining. Before performing all procedures, free-floating tissues were rinsed three times over a period of $10 \mathrm{~min}$ in PBS buffer.

Immunohistochemistry. Immunoreactivity for $\mathrm{Cd} 11 \mathrm{~b} / \mathrm{c}$ (Abcam, ab1211) was detected using a conventional avidin-biotin-immunoperoxidase technique ${ }^{62}$. The tissues were labelled with a cell type-specific monoclonal mouse antibody against $\mathrm{Cd} 11 \mathrm{~b} / \mathrm{c}(1: 500)$. Floating tissues were treated with $3 \%$ hydrogen peroxide for 10 min to quench endogenous peroxidase activity, rinsed three times in PBS and then incubated in 1.0\% sodium borohydride for 6 to $8 \mathrm{~min}$ to reduce free aldehydes. The tissues were then incubated with blocking solution $(5 \%$ BSA, $2 \%$ goat or rabbit serum, $1 \%$ Triton X-100 in PBS) for $1 \mathrm{~h}$ to decrease non-specific labelling. The tissues were later incubated with primary antibodies at room temperature overnight. After washing, the primary antibodies were detected with a biotinylated secondary antibody (1:1000; Santa Cruz Biotechnology, CA) and an avidin/ biotin system (VECTASTAIN Elite ABC kit, Vector Laboratories, Burlingame, CA). Images were collected with an Olympus microscope and analysed using ImageJ free software.

Immunofluorescence. Labelling for Syp, Map2 and Tau proteins was performed on free-floating brain tissues. The tissues were treated with $0.1 \%$ sodium citrate at $4{ }^{\circ} \mathrm{C}$ for $30 \mathrm{~min}$, incubated in $0.1 \%$ Triton X-100 in PBS for $30 \mathrm{~min}$ at room temperature and blocked with blocking solution (5\% bovine serum albumin, $2 \%$ normal goat serum, $0.1 \%$ Triton X-100 and $0.05 \%$ Tween 20 in PBS) for $1 \mathrm{~h}$ before incubation with the primary antibodies. The tissues were incubated overnight with monoclonal mouse anti-Syp (1:500; Santa Cruz Biotechnology SC-123737), mouse anti-Map2 (1:500; Santa Cruz Biotechnology SC-51669) and mouse anti-Tau (1:1000; Cell Signaling 4019) antibodies in 50\% blocking solution with PBS. The tissues were rinsed three times in PBS for 10 min each and incubated in the dark with Alexa 647-conjugated anti-mouse IgG (1:500, Thermo Fisher Scientific) secondary antibodies for $1 \mathrm{~h}$. After washing, the nuclei were stained for $5 \mathrm{~min}$ in a $1 \mu \mathrm{L} / \mathrm{mL}$ 6-diamidino-2-phenylindole-dihydrochloride (DAPI) solution (Boehringer Mannheim GmbH, Mannheim, Germany), and the tissues were coverslipped with fluorescence mounting medium (DAKO, Santa Clara, CA, USA). The control tissues were treated in the same way but without the primary antibodies. Images were collected with a Nikon confocal microscope.

Statistical analysis. All numerical data are expressed as the mean $\pm \mathrm{SD}$ and were calculated from three independent experiments. Statistical analysis of each data series was performed using one-way analysis of variance (ANOVA) followed by a post hoc analysis with a Newman-Keuls test and paired T-tests using Graph Prism 7 (GraphPad Software, Inc., La Jolla, CA, USA). A p-value $\leq 0.05$ was considered to indicate a significant difference. To rank the abundance (enrichment) of genes and functional clusters, an enrichment score was calculated as the geometric mean of all the enrichment p-values for each annotation term associated with the gene in the brain functions ${ }^{63}$. Higher enrichment scores were indicative of a greater response of the gene members to the specific treatment, and in the case of functional clusters, a cut-off of 1.3 was used, as recommended by Huang et al. ${ }^{61}$. The p-value was determined using a modified Fisher's exact test with a default cut-off of 0.1. Smaller p-values indicated greater significance of the enrichment of individual gene terms.

\section{Data Availability}

Accession number: GSE119435.

\section{References}

1. Bole-Feysot, C., Goffin, V., Edery, M., Binart, N. \& Kelly, P. A. Prolactin (PRL) and its receptor: actions, signal transduction pathways and phenotypes observed in PRL receptor knockout mice. Endocr Rev 19, 225-268, https://doi.org/10.1210/edrv.19.3.0334 (1998).

2. Marano, R. J. \& Ben-Jonathan, N. Minireview: Extrapituitary prolactin: an update on the distribution, regulation, and functions. Mol Endocrinol 28, 622-633, https://doi.org/10.1210/me.2013-1349 (2014).

3. Cabrera-Reyes, E. A., Limón-Morales, O., Rivero-Segura, N. A., Camacho-Arroyo, I. \& Cerbón, M. Prolactin function and putative expression in the brain. Endocrine 57, 199-213, https://doi.org/10.1007/s12020-017-1346-x (2017).

4. Eichenbaum, H. Hippocampus: cognitive processes and neural representations that underlie declarative memory. Neuron 44, 109-120, https://doi.org/10.1016/j.neuron.2004.08.028 (2004).

5. Kinsley, C. H. et al. Motherhood improves learning and memory. Nature 402, 137-138, https://doi.org/10.1038/45957 (1999).

6. Love, G. et al. Maternal experience produces long-lasting behavioral modifications in the rat. Behav Neurosci 119, 1084-1096, https://doi.org/10.1037/0735-7044.119.4.1084(2005).

7. Pawluski, J. L., Walker, S. K. \& Galea, L. A. Reproductive experience differentially affects spatial reference and working memory performance in the mother. Horm Behav 49, 143-149, https://doi.org/10.1016/j.yhbeh.2005.05.016 (2006).

8. Walker, T. L. et al. Prolactin stimulates precursor cells in the adult mouse hippocampus. PLoS One 7, e44371, https://doi.org/10.1371/ journal.pone.0044371 (2012).

9. Shingo, T. et al. Pregnancy-stimulated neurogenesis in the adult female forebrain mediated by prolactin. Science 299, 117-120, https://doi.org/10.1126/science.1076647 (2003).

10. Pawluski, J. L. \& Galea, L. A. Reproductive experience alters hippocampal neurogenesis during the postpartum period in the dam. Neuroscience 149, 53-67, https://doi.org/10.1016/j.neuroscience.2007.07.031 (2007).

11. Mak, G. K. \& Weiss, S. Paternal recognition of adult offspring mediated by newly generated CNS neurons. Nat Neurosci 13, 753-758, https://doi.org/10.1038/nn.2550 (2010).

12. Kinsley, C. H. et al. Motherhood and the hormones of pregnancy modify concentrations of hippocampal neuronal dendritic spines. Horm Behav 49, 131-142, https://doi.org/10.1016/j.yhbeh.2005.05.017 (2006). 
13. Pawluski, J. L. \& Galea, L. A. Hippocampal morphology is differentially affected by reproductive experience in the mother. J Neurobiol 66, 71-81, https://doi.org/10.1002/neu.20194 (2006).

14. Larsen, C. M. \& Grattan, D. R. Prolactin, neurogenesis, and maternal behaviors. Brain Behav Immun 26, 201-209, https://doi. org/10.1016/j.bbi.2011.07.233 (2012).

15. Ferraris, J., Bernichtein, S., Pisera, D. \& Goffin, V. Use of prolactin receptor antagonist to better understand prolactin regulation of pituitary homeostasis. Neuroendocrinology 98, 171-179, https://doi.org/10.1159/000354701 (2013).

16. Patil, M. J., Henry, M. A. \& Akopian, A. N. Prolactin receptor in regulation of neuronal excitability and channels. Channels (Austin) 8, 193-202 (2014).

17. Vanoye-Carlo, A., Morales, T., Ramos, E., Mendoza-Rodríguez, A. \& Cerbón, M. Neuroprotective effects of lactation against kainic acid treatment in the dorsal hippocampus of the rat. Horm Behav 53, 112-123, https://doi.org/10.1016/j.yhbeh.2007.09.004 (2008).

18. Tejadilla, D., Cerbón, M. \& Morales, T. Prolactin reduces the damaging effects of excitotoxicity in the dorsal hippocampus of the female rat independently of ovarian hormones. Neuroscience 169, 1178-1185, https://doi.org/10.1016/j.neuroscience.2010.05.074 (2010).

19. Cabrera, V. et al. Lactation reduces glial activation induced by excitotoxicity in the rat hippocampus. J Neuroendocrinol 25, 519-527, https://doi.org/10.1111/jne.12028 (2013).

20. Vergara-Castañeda, E. et al. Prolactin mediates neuroprotection against excitotoxicity in primary cell cultures of hippocampal neurons via its receptor. Brain Res 1636, 193-199, https://doi.org/10.1016/j.brainres.2016.02.011 (2016).

21. Rivero-Segura, N. A. et al. Prolactin-induced neuroprotection against glutamate excitotoxicity is mediated by the reduction of [Ca2+]i overload and NF- $\kappa$ B activation. PLoS One 12, e0176910, https://doi.org/10.1371/journal.pone.0176910 (2017).

22. Charoenphandhu, N., Wongdee, K., Teerapornpuntakit, J., Thongchote, K. \& Krishnamra, N. Transcriptome responses of duodenal epithelial cells to prolactin in pituitary-grafted rats. Mol Cell Endocrinol 296, 41-52, https://doi.org/10.1016/j.mce.2008.09.025 (2008).

23. Wanyonyi, S. S., Kumar, A., Du Preez, R., Lefevre, C. \& Nicholas, K. R. Transcriptome analysis of mammary epithelial cell gene expression reveals novel roles of the extracellular matrix. Biochem Biophys Rep 12, 120-128, https://doi.org/10.1016/j. bbrep.2017.08.013 (2017)

24. Bordin, S. et al. Prolactin-modulated gene expression profiles in pancreatic islets from adult female rats. Mol Cell Endocrinol 220, 41-50, https://doi.org/10.1016/j.mce.2004.04.001 (2004).

25. Noel, M. B. \& Woodside, B. Effects of systemic and central prolactin injections on food intake, weight gain, and estrous cyclicity in female rats. Physiol Behav 54, 151-154 (1993).

26. Obál, F. et al. Rapid eye movement sleep is reduced in prolactin-deficient mice. J Neurosci 25, 10282-10289, https://doi.org/10.1523/ JNEUROSCI.2572-05.2005 (2005).

27. Grattan, D. R. \& Kokay, I. C. Prolactin: a pleiotropic neuroendocrine hormone. J Neuroendocrinol 20, 752-763, https://doi. org/10.1111/j.1365-2826.2008.01736.x (2008).

28. Patil, M. J., Green, D. P., Henry, M. A. \& Akopian, A. N. Sex-dependent roles of prolactin and prolactin receptor in postoperative pain and hyperalgesia in mice. Neuroscience 253, 132-141, https://doi.org/10.1016/j.neuroscience.2013.08.035 (2013).

29. Patil, M. J., Ruparel, S. B., Henry, M. A. \& Akopian, A. N. Prolactin regulates TRPV1, TRPA1, and TRPM8 in sensory neurons in a sex-dependent manner: Contribution of prolactin receptor to inflammatory pain. Am J Physiol Endocrinol Metab 305, E1154-1164, https://doi.org/10.1152/ajpendo.00187.2013 (2013).

30. Mena, F. et al. Prolactin fractions from lactating rats elicit effects upon sensory spinal cord cells of male rats. Neuroscience $\mathbf{2 4 8}$ 552-561, https://doi.org/10.1016/j.neuroscience.2013.06.052 (2013).

31. Stevens, B. et al. The classical complement cascade mediates CNS synapse elimination. Cell 131, 1164-1178, https://doi. org/10.1016/j.cell.2007.10.036 (2007).

32. Schafer, D. P. et al. Microglia sculpt postnatal neural circuits in an activity and complement-dependent manner. Neuron 74, 691-705, https://doi.org/10.1016/j.neuron.2012.03.026 (2012).

33. Stephan, A. H., Barres, B. A. \& Stevens, B. The complement system: an unexpected role in synaptic pruning during development and disease. Annu Rev Neurosci 35, 369-389, https://doi.org/10.1146/annurev-neuro-061010-113810 (2012).

34. Squarzoni, P. et al. Microglia modulate wiring of the embryonic forebrain. Cell Rep 8, 1271-1279, https://doi.org/10.1016/j. celrep.2014.07.042 (2014).

35. Heppner, F. L., Ransohoff, R. M. \& Becher, B. Immune attack: the role of inflammation in Alzheimer disease. Nat Rev Neurosci 16, 358-372, https://doi.org/10.1038/nrn3880 (2015).

36. Hong, H., Kim, B. S. \& Im, H. I. Pathophysiological Role of Neuroinflammation in Neurodegenerative Diseases and Psychiatric Disorders. Int Neurourol J 20, S2-7, https://doi.org/10.5213/inj.1632604.302 (2016).

37. Hong, S. \& Stevens, B. Microglia: Phagocytosing to Clear, Sculpt, and Eliminate. Dev Cell 38, 126-128, https://doi.org/10.1016/j. devcel.2016.07.006 (2016).

38. Wolf, G. et al. Differentially Severe Cognitive Effects of Compromised Cerebral Blood Flow in Aged Mice: Association with Myelin Degradation and Microglia Activation. Front Aging Neurosci 9, 191, https://doi.org/10.3389/fnagi.2017.00191 (2017).

39. York, E. M., Bernier, L. P. \& MacVicar, B. A. Microglial modulation of neuronal activity in the healthy brain. Dev Neurobiol 78, 593-603, https://doi.org/10.1002/dneu.22571 (2018).

40. Cabrera, V. et al. Lactation is a natural model of hippocampus neuroprotection against excitotoxicity. Neurosci Lett 461, 136-139, https://doi.org/10.1016/j.neulet.2009.06.017 (2009).

41. Möderscheim, T. A. et al. Prolactin is involved in glial responses following a focal injury to the juvenile rat brain. Neuroscience 145, 963-973, https://doi.org/10.1016/j.neuroscience.2006.12.053 (2007).

42. Pósfai, B., Cserép, C., Orsolits, B. \& Dénes, Á. New Insights into Microglia-Neuron Interactions: A Neuron’s Perspective. Neuroscience, https://doi.org/10.1016/j.neuroscience.2018.04.046 (2018).

43. Mustafa, A. et al. Prolactin binding sites in rat brain and liver: effects of long-term ovariectomy and ovarian steroids. Neurosci Lett 200, 179-182 (1995).

44. Sárvári, M., Kalló, I., Hrabovszky, E., Solymosi, N. \& Liposits, Z. Ovariectomy Alters Gene Expression of the Hippocampal Formation in Middle-Aged Rats. Endocrinology 158, 69-83, https://doi.org/10.1210/en.2016-1516 (2017).

45. Temido-Ferreira, M. et al. Age-related shift in LTD is dependent on neuronal adenosine A. Mol Psychiatry, https://doi.org/10.1038/ s41380-018-0110-9 (2018).

46. Horgusluoglu-Moloch, E. et al. Targeted neurogenesis pathway-based gene analysis identifies ADORA2A associated with hippocampal volume in mild cognitive impairment and Alzheimer's disease. Neurobiol Aging 60, 92-103, https://doi.org/10.1016/j. neurobiolaging.2017.08.010 (2017).

47. Ortiz-Pérez, A., Limón-Morales, O., Rojas-Castañeda, J. C., Cerbón, M. \& Picazo, O. Prolactin prevents the kainic acid-induced neuronal loss in the rat hippocampus by inducing prolactin receptor and putatively increasing the VGLUT1 overexpression. Neurosci Lett, https://doi.org/10.1016/j.neulet.2018.11.052 (2018).

48. Rocchetti, J. et al. Presynaptic D2 dopamine receptors control long-term depression expression and memory processes in the temporal hippocampus. Biol Psychiatry 77, 513-525, https://doi.org/10.1016/j.biopsych.2014.03.013 (2015).

49. Huck, J. H. et al. De novo expression of dopamine D2 receptors on microglia after stroke. J Cereb Blood Flow Metab 35, 1804-1811, https://doi.org/10.1038/jcbfm.2015.128 (2015). 
50. Zhang, B., Ma, K. \& Li, B. Inflammatory reaction regulated by microglia plays a role in atrazine-induced dopaminergic neuron degeneration in the substantia nigra. J Toxicol Sci 40, 437-450, https://doi.org/10.2131/jts.40.437 (2015).

51. Zhang, H. et al. Neurotensinergic Excitation of Dentate Gyrus Granule Cells via Goq-Coupled Inhibition of TASK-3 Channels. Cereb Cortex 26, 977-990, https://doi.org/10.1093/cercor/bhu267 (2016).

52. Ito-Ishida, A. et al. Presynaptically released Cbln1 induces dynamic axonal structural changes by interacting with GluD2 during cerebellar synapse formation. Neuron 76, 549-564, https://doi.org/10.1016/j.neuron.2012.07.027 (2012).

53. Shelly, M. et al. Semaphorin3A regulates neuronal polarization by suppressing axon formation and promoting dendrite growth. Neuron 71, 433-446, https://doi.org/10.1016/j.neuron.2011.06.041 (2011).

54. Alvarez-López, M. J. et al. Long-term exercise modulates hippocampal gene expression in senescent female mice. J Alzheimers Dis 33, 1177-1190, https://doi.org/10.3233/JAD-121264 (2013).

55. Noh, H. S. et al. Ketogenic diet decreases the level of proenkephalin mRNA induced by kainic acid in the mouse hippocampus. Neurosci Lett 395, 87-92, https://doi.org/10.1016/j.neulet.2005.10.073 (2006).

56. Merchenthaler, I., Lennard, D. E., Cianchetta, P., Merchenthaler, A. \& Bronstein, D. Induction of proenkephalin in tuberoinfundibular dopaminergic neurons by hyperprolactinemia: the role of sex steroids. Endocrinology 136, 2442-2450, https:// doi.org/10.1210/endo.136.6.7750466 (1995).

57. Larsen, P. J. \& Mau, S. E. Effect of acute stress on the expression of hypothalamic messenger ribonucleic acids encoding the endogenous opioid precursors preproenkephalin A and proopiomelanocortin. Peptides 15, 783-790 (1994).

58. Montejo, Á. et al. Spanish consensus on the risks and detection of antipsychotic drug-related hyperprolactinaemia. Rev Psiquiatr Salud Ment 9, 158-173, https://doi.org/10.1016/j.rpsm.2015.11.003 (2016).

59. Petruzzelli, M. G. et al. Hyperprolactinemia and insulin resistance in drug naive patients with early onset first episode psychosis. BMC Psychiatry 18, 246, https://doi.org/10.1186/s12888-018-1827-3 (2018)

60. Lally, J. et al. Hyperprolactinaemia in first episode psychosis - A longitudinal assessment. Schizophr Res 189, 117-125, https://doi. org/10.1016/j.schres.2017.07.037 (2017).

61. Dennis, G. et al. DAVID: Database for Annotation, Visualization, and Integrated Discovery. Genome Biol 4, P3 (2003).

62. Sawchenko, P. E., Arias, C. \& Bittencourt, J. C. Inhibin beta, somatostatin, and enkephalin immunoreactivities coexist in caudal medullary neurons that project to the paraventricular nucleus of the hypothalamus. J Comp Neurol 291, 269-280, https://doi. org/10.1002/cne.902910209 (1990).

63. Huang, dW., Sherman, B. T. \& Lempicki, R. A. Systematic and integrative analysis of large gene lists using DAVID bioinformatics resources. Nat Protoc 4, 44-57, https://doi.org/10.1038/nprot.2008.211 (2009).

\section{Acknowledgements}

This work was submitted in fulfilment of the requirements to obtain a PhD degree at the Programa de Doctorado en Ciencias Biomédicas at the Universidad Nacional Autónoma de México (UNAM). The authors give thanks to Diana Elisa García-Cortés from the Instituto Nacional de Ciencias Genómica and Verónica Jiménez-Jacinto from the Unidad Universitaria de Secuenciación Masiva y Bioinformática, UNAM, for bioinformatics help; to Lucía Macias-Rosales from the Unidad de Experimentación Animal de la Facultad de Química and Maria Eugenia Ramos-Aguilar from the Instituto de Neurobiología, UNAM, for their technical assistance; to Karla MacDonald, UNAM, for the English revision of the manuscript; and to Pedro Cuauhtémoc Tonatiuh Collazo Saldaña from the Instituto de Ciencias Biomédicas, UNAM, for the confocal micrographs. This investigation was performed using financial support from PAPIIT IN216817, UNAM, and the National Institute of Perinatology, CDMX, México. América Vanoye Carlo was supported by the E022 Program of the National Institute of Pediatrics, SS, CDMX., México. Erika Alejandra Cabrera Reyes is a doctoral student from the Programa de Doctorado en Ciencias Biomédicas, Universidad Nacional Autónoma de México (UNAM), and received fellowship 231335 from CONACYT.

\section{Author Contributions}

E.A.C.-R. and M.C. conceived the experiments. E.A.C.-R., N.A.R.-S. and O.C.-N. performed the surgeries and administered the treatments. E.A.C.-R. and A.V.-C. dissected the hippocampi. E.A.C.-R. performed the data analysis. E.R.V.-M. extracted and quantified the total RNA. E.A.C.-R. contributed to the bioinformatic analysis for RNASeq. E.A.C.-R. and M.R.-D. contributed to the analysis of differential gene expression. E.A.C.-R. performed the RT-qPCR validation. E.A.C.-R. and A.V.-C. performed the immunoassays. E.A.C.-R., M.C. and A.V.-C. wrote the paper. All authors reviewed the manuscript.

\section{Additional Information}

Supplementary information accompanies this paper at https://doi.org/10.1038/s41598-019-50228-7.

Competing Interests: The authors declare no competing interests.

Publisher's note Springer Nature remains neutral with regard to jurisdictional claims in published maps and institutional affiliations.

(c) (i) Open Access This article is licensed under a Creative Commons Attribution 4.0 International cc. License, which permits use, sharing, adaptation, distribution and reproduction in any medium or format, as long as you give appropriate credit to the original author(s) and the source, provide a link to the Creative Commons license, and indicate if changes were made. The images or other third party material in this article are included in the article's Creative Commons license, unless indicated otherwise in a credit line to the material. If material is not included in the article's Creative Commons license and your intended use is not permitted by statutory regulation or exceeds the permitted use, you will need to obtain permission directly from the copyright holder. To view a copy of this license, visit http://creativecommons.org/licenses/by/4.0/.

(C) The Author(s) 2019 